\title{
Psychosocial and socioeconomic burden of vasomotor symptoms in menopause: A comprehensive review Wulf H Utian*
}

\author{
Address: North American Menopause Society, 5900 Lander Brook Drive, Mayfield Heights, OH 44124, USA \\ Email: Wulf H Utian* - utian@menopause.org \\ * Corresponding author
}

Published: 05 August 2005

Health and Quality of Life Outcomes 2005, 3:47 doi:10.1 186/1477-7525-3-

47

This article is available from: http://www.hqlo.com/content/3/I/47

(c) 2005 Utian; licensee BioMed Central Ltd.

This is an Open Access article distributed under the terms of the Creative Commons Attribution License (http://creativecommons.org/licenses/by/2.0), which permits unrestricted use, distribution, and reproduction in any medium, provided the original work is properly cited.
Received: 22 June 2005

Accepted: 05 August 2005

\begin{abstract}
Many women experience vasomotor symptoms at or around the time of menopause. Hot flushes and night sweats are considered primary menopausal symptoms that may also be associated with sleep and mood disturbances, as well as decreased cognitive function. All of these symptoms may lead to social impairment and work-related difficulties that significantly decrease overall quality of life. Hot flushes have shown a great deal of variability in their frequency and severity in women. In some women, hot flushes persist for several months; in others, they may last for more than 10 years. Traditionally vasomotor symptoms were reported to begin 5 to 10 years prior to the cessation of the final menstrual cycle, corresponding with the initial decline in circulating gonadal hormones; however, night sweats in particular most often begin in perimenopause. The pathogenesis of hot flushes has not yet been fully elucidated, but the circuitry involving estrogen and neurotransmitters, norepinephrine and serotonin specifically, are hypothesized to play a major role in the altered homeostatic thermoregulatory mechanisms underlying these events.

Menopause-associated vasomotor symptoms are associated with significant direct and indirect costs. Overall costs of traditional pharmacotherapy or complementary and alternative medicine modalities, including over-the-counter treatments and dietary supplements, for managing menopause-related vasomotor symptoms are substantial and include initial and follow-up physician visits and telephone calls. Additional costs include laboratory testing, management of adverse events, loss of productivity at work, and personal and miscellaneous costs. Pharmacoeconomic analyses, including those that consider risks identified by the Women's Health Initiative, generally support the cost-effectiveness of hormonal therapy for menopause-associated vasomotor symptoms, which have been the mainstay for the management of these symptoms for more than 50 years. However, because many women now want to avoid hormone therapy, there is a need for additional targeted therapies, validated by results from controlled clinical trials that are safe, efficacious, cost-effective, and well tolerated by symptomatic menopausal women.
\end{abstract}

\section{Review}

Menopause is characterized by physiologic and psychosocial changes in a woman's life. Menopause may be associ- ated with vasomotor symptoms (VMS; hot flushes [also referred to as hot flashes] and night sweats), bone loss, urogenital atrophy, urinary tract infections and 
incontinence, increased cardiovascular risk, somatic symptoms, sexual dysfunction and decreased libido, and loss of skin elasticity. VMS, and the sleep and mood disturbances that often result from them, can have a significant negative impact on overall quality of life (QOL) for a substantial number of women. The impact of VMS has gained in importance as the lifespan of women has increased throughout the world since women can expect to spend a significant portion of their lives after menopause. This period should be a highly productive time for women, and maintaining functional ability and a good QOL is of utmost importance. Accordingly, it is important to understand the economic and QOL impacts of menopausal VMS as well as the most recent pharmacoeconomic analyses of different approaches to managing symptoms. Thus, the aims of this paper are to briefly review the epidemiology of VMS, describe what is known about the physiologic basis of these symptoms, and examine the global and health-related quality of life (HRQOL) effects of VMS in women, with a focus on psychosocial and economic impairments, and costs associated with treatments.

\section{Epidemiology of VMS \\ Prevalence and risk factors}

Recent US Census Bureau statistics indicate that approximately one third of women are older than 50 years of age [1]. It is estimated that $75 \%$ of women in this age group will experience hot flushes, a value supported by a recent longitudinal study of 454 women who were followed from premenopause to postmenopause [2]. Thus, in the United States alone, there are approximately 40 to $50 \mathrm{mil}-$ lion women who experience hot flushes [1]. Worldwide, between $50 \%$ and $85 \%$ of women (approximately 360 million) older than 45 years of age experience hot flushes [3]. The prevalence of hot flushes varies widely across populations and is strongly influenced by culture and ethnicity. In the United States, the Study of Women's Health Across the Nation (SWAN) surveyed more than 16,000 women and found that the prevalence of hot flushes was highest among African Americans (46\%), followed by Hispanics (34\%), whites (31\%), Chinese (21\%), and Japanese (18\%) [4]. In other parts of the world, rates of hot flushes vary widely as well, with the lowest prevalence observed in China (10\%) and other Asian nations [5].

Many attempts have been made to identify demographic characteristics associated with a significantly increased risk of hot flushes. For many years, low body mass index (BMI) and race were considered significant predictors of VMS, with thin, white women believed to at the highest risk for hot flushes. More recent findings have suggested that high BMI and African American race are associated with a higher risk of VMS. This shift may be related to better sampling of the general population by major clinical trials because, traditionally, white middle-class women participated in clinical trials that often did not include women from other ethnic groups. The multiethnic SWAN not only demonstrated a link between an elevated BMI $\left(\geq 27 \mathrm{~kg} / \mathrm{m}^{2}\right.$ ) and hot flushes [4], but an increased prevalence in African American women, as mentioned. Ongoing studies continue to investigate potential predictors of hot flushes. Smoking, maternal history, history of premenstrual complaints, elevated basal core body temperature, low physical activity, low socioeconomic status, and low levels of estrogen and high levels of luteinizing and follicle-stimulating hormones prior to the menopausal transition have all been associated with an increased risk of hot flushes [4,6-8].

\section{Timing of hot flushes}

The timing and frequency of hot flushes have been reviewed by several researchers [9]. SWAN demonstrated that hot flushes occur earlier than previously believed and may become less frequent and less intense as menopause progresses. SWAN data indicated that VMS were more frequently reported by women in late perimenopause with a relative risk for hot flushes at 1.0 during premenopause (the 1 or 2 years prior to menopause), 2.06 during early perimenopause (the early menopausal transition), 4.32 during late perimenopause (the late menopausal transition), and 2.81 during postmenopause [4]. The frequency of hot flushes varies but tends to remain consistent for an individual [10]. Many women have hot flushes on a daily basis, some as frequently as every hour, whereas others have VMS infrequently (ie, weekly or monthly) [10]. The majority of women experience hot flushes for 6 months to 2 years, with the highest number of women reporting symptoms during the first 2 postmenopausal years $[9,10]$. However, in another study, 26\% of women reported having hot flushes for 6 to 10 years, whereas $10 \%$ have had VMS for more than 10 years [11].

\section{Pathophysiology}

The cause of hot flushes has yet to be determined because of the limited research focus in this therapeutic area. Hot flushes are believed to result from the brain's response to diminished hormones and hormonal fluctuations that occur during the menopausal transition. Ovarian hormones have been shown to influence thermoregulatory mechanisms that regulate temperature homeostasis in the hypothalamus. The neurotransmitters serotonin and norepinephrine play a role in modulating core body temperature, neurochemical messaging, and peripheral vasculature [12]. Kronenberg and colleagues were the first investigators to document cardiovascular, temperature, hormonal, and autonomic parameters with hot flushes and link them with thermoregulatory mechanisms [13], with more recent mechanistic information published by Freedman [14] and Deecher et al. [12]. 


\section{Effects of associated VMS on QOL}

Perceived QOL is difficult to measure and there is no universal agreement on how it should be quantified. Objective measurements of health status (often referred to as HRQOL) may not capture the patient's perception of overall life satisfaction. QOL can be defined as a reflection of an individual's belief about functioning and achievement. HRQOL may be viewed as the individual's perception regarding her physical, cognitive, and mental health as well as social situation [15]. Assessments of overall QOL for menopausal women must include consideration of somatic symptoms (hot flushes, night sweats, urogenital atrophy), psychological symptoms (depression, mood swings, irritability, anxiety), and life circumstances (function in the workplace). Thus, overall QOL may include four major factors: occupational, health-related, sexual, and emotional [15]. Consideration of HRQOL is also influenced by women's increased risk of multiple chronic diseases associated with menopause, including osteopenia, osteoporosis and related fractures, and cardiovascular disease [16].

\section{VMS-related effects on QOL}

VMS can have a significant negative impact on QOL in younger and older women, contributing to physical as well as psychosocial impairment (Table 1). Becoming flushed and sweating profusely in a social or work-related situation may cause extreme anxiety for many women and lead to social isolation [17].

Although it is generally accepted that VMS are troubling to many women and adversely impact their QOL, these effects are difficult to quantify because of the many factors that contribute to overall QOL satisfaction. For example, an objective of the Women's Health Initiative (WHI) was to determine whether hormonal therapy (HT) could reverse impaired HRQOL in 16,608 women aged 50 to 79 years. Results from this analysis indicated that estrogen plus progesterone did not yield any significant benefits in any of the HRQOL outcomes when compared with placebo over 3 years of follow-up [18]. However, this investigation did not examine global QOL in relation to VMS as an a priori outcome, and the women studied were not only excluded if the investigators felt they were having significant VMS that would interfere with long-term study involvement, but were older than those who typically have VMS and use HT. Another limitation was the use of a QOL questionnaire that may have been inadequate for determining the global impact of VMS. More recently, a new QOL scale has been designed specifically for the perimenopausal population [19]: The Utian Quality of Life (UQOL) Scale evaluates occupational, health, emotional, and sexual QOL. This 23-item assessment should increase the reliability of QOL measurement in perimenopausal and postmenopausal women.
Table I: Vasomotor Symptoms and Related Psychosocial Impairment During the Menopausal Transition

Hot flushes
Night sweats
Sleep disturbances
Insomnia
Sleep apnea
Mood swings
Irritability
Sadness
Tension
Cognitive deficits
Poor concentration
Verbal memory problems
Social impairment
Disruption of family relationships
Social isolation
Work-related difficulties
Reduced productivity
Other Quality-of-life impairment
Embarrassment
Anxiety
Fatigue

The physiologic changes associated with menopause often result in increased anxiety and stress. These feelings may arise from sleep deprivation, mood swings, and unpredictable hot flushes. Before menopause, most women have a monthly hormonal rhythm. When the cycle becomes disrupted by erratic hormonal fluctuations, a woman's sense of well-being can be disturbed. These changes also tend to occur at a time when women are more likely to experience other life changes, including divorce, widowhood, children leaving home, concerns about aging parents, and other caregiving issues. Selfimage is another important variable, and women with poor self-images have more flush-related distress [20]. In combination, these factors may each contribute to a reduced global QOL as well as decreased work productivity and difficulties with personal and social relationships.

A large number of studies have documented the negative impact of menopause on QOL. Ledesert and colleagues studied a cohort of 289 women aged 45 to 52 years who were no longer menstruating and reported lower HRQOL on several measures of the Nottingham Health Profile compared with values for menstruating women [21]. A population-based study evaluated the effects of various medical conditions on work impairment in more than 16,500 individuals [22]. Menopause was one of the factors associated with significant work limitations. The impact of VMS on HRQOL has also been studied by Bobula and colleagues, who evaluated 1,655 healthy, nonhysterectomized, postmenopausal women ranging in age 
from 40 to 65 years who were not receiving HT [23]. Their results indicated a significant correlation between moderate to severe hot flushes and decreased QOL. Women with moderate to severe hot flushes had significantly poorer scores than women with no hot flushes on four of the eight 36-item Short Form Health Survey (SF-36) subscales (vitality, bodily pain, social function, and role limitations-emotional), the mental composite score, and the Women's Health Questionnaire (WHQ), with pronounced differences for VMS, sleep problems, sexual behavior, and somatic symptoms. Women with moderate to severe hot flushes also had significantly poorer scores than women with mild hot flushes on two of the eight SF36 subscales (vitality and social function) and five of the nine WHQ domains, including VMS, sleep problems, sexual behavior, somatic symptoms, and depressed mood. Finally, women with mild hot flushes had significantly worse scores than women with no hot flushes on two of the eight SF-36 subscales (vitality and role limitationsemotional) and on the WHQ for VMS, sleep problems, somatic symptoms, memory/concentration, and menstrual symptoms.

\section{Impact of VMS on sleep, mood, and cognitive function} Despite the lack of agreement in the medical literature about the relationship between VMS on sleep quality, mood variability, and cognitive function, these symptoms are, in fact, primary complaints of menopausal women to their healthcare practitioners; as such, they are addressed in this review.

\section{Sleep disturbances}

The causes of menopause-related sleep disturbances are controversial. It has been suggested that problems with sleep may occur in older women independently of menopause. For example, nocturia increases with age and may disturb sleep [24]. Depression, stress, and other factors (eg, restless leg and other periodic limb movement syndromes) may also contribute to sleep disturbances in these patients [25].

Sleep disturbances also have been specifically related to hormonal changes that trigger hot flushes or night sweats, independent of age. A National Sleep Foundation poll of 1,000 women between the ages of 30 and 60 years found that $36 \%$ of perimenopausal, postmenopausal, and oophorectomized women experienced hot flushes during the night [26]. In this study, $44 \%$ of women who experienced VMS while sleeping were perimenopausal versus $28 \%$ of women who were postmenopausal. The poll also showed that menopausal and postmenopausal women slept less than premenopausal women. According to the National Sleep Foundation, women with night sweats experienced an average of three occurrences per week.
These events disrupted sleep and led to daytime irritability [26].

Menopause-related VMS also may be associated with insomnia and disordered breathing at night. More perimenopausal and postmenopausal women than menstruating women have difficulty falling asleep, staying asleep, and achieving refreshing sleep [26]. Insomnia symptoms in women in the various stages of menopause include difficulty falling asleep (29\%) and early awakening with an inability to fall back to sleep $(21 \%)$. Respiratory abnormalities also may contribute to sleep disturbances in menopausal women. Results from a study of 589 women indicated that those in the menopausal transition were at a greater risk for complaints of sleep apnea and hypopnea than were younger women [27]. Postmenopausal women had a 2.6-to 3.5-fold greater rate of sleep-disordered breathing than their premenopausal counterparts [27]. Because sleep complaints are part of menopause-associated VMS, disordered breathing is often overlooked as a potential cause of menopause-associated sleep disturbance [27]. Although these and other results have suggested a correlation between the occurrence of hot flushes and sleep complaints in menopausal women, only a few studies have employed objective methods for sleep evaluation (eg, polysomnography, actigraphy, quantitative electroencephalographic analysis). Results from these assessments have indicated that hot flushes correlate with the occurrence of objectively demonstrable sleep disruption in at least some women [28].

Inadequate and unrefreshing sleep can have many consequences. Over time, disruption of sleep secondary to hot flushes and/or night sweats leads to chronic sleep deficits, significantly impaired alertness and mental acuity, carelessness, forgetfulness, and decreased work productivity. In some cases, night sweats can drench bedclothes and sheets, further disrupting sleep and necessitating a change of clothes and covers, which can also disturb the sleep of the individual's bed partner. Thus, lack of sleep, tiredness, and irritability can affect daytime productivity as well as familial and social relationships.

\section{Mood}

Menopause-associated changes in mood may result from a wide range of variables, including elevated sensitivity to environmental events secondary to decreased hormonal levels, changes in socioeconomic and/or marital status, culture, lifestyle factors, level of education, and history of depressive symptoms $[29,30]$. Longitudinal and cross-sectional studies carried out to date have not indicated a consistent relationship between the menopausal transition and increased risk of mood disorders [31,32]. However, results from the prospective population-based Melbourne Women's Midlife Health Project, which followed 438 
women for 11 years and used the Center for Epidemiologic Studies Depression Scale to measure depression, indicated that depression scores were highest for women who were in the menopause transition stage (ie, had not reached their final menstrual period) or who had experienced surgical menopause. Current use of HT was associated with lower Center for Epidemiologic Studies Depression Scale scores (ie, less severe depressive symptoms) in this cohort [33]. These epidemiologic results are consistent with those from a small-scale clinical trial that demonstrated the significant benefit of short-term HT in perimenopausal women with depression [34]. It is important to note that many studies investigating mood and VMS have used depression scales. There are important distinctions between mood variability and major depression. It is incorrect to interpret the results from depression and simply extrapolate these findings to mood. Hopefully, new studies will address this issue and develop specific scales to delineate the impact of VMS on mood.

\section{Cognitive decline}

Memory impairment is directly related to hot flushes in women who have undergone oophorectomy, but natural menopause itself does not necessarily result in significant cognitive dysfunction [35]. During a hot flush, blood flow decreases in the hippocampus, possibly impairing memory and cognition [35]. It has been suggested that such reductions in blood flow may contribute to the decreased mental clarity and short-term verbal memory problems experienced by many perimenopausal and postmenopausal women [35]. The importance of estrogen in cognition has been demonstrated by Jacobs and colleagues, who measured cognitive function and verbal memory in 727 older women (average age, 74.2 years). Study results demonstrated that cognitive test scores and verbal memory were superior in the women who received HT compared with those who did not [36].

\section{Costs associated with VMS and their treatment}

In the year 2000, there were approximately 50 million women aged 45 to 60 years in the United States; as life expectancy increases, that number will increase [1]. Many of these women will use the health care system for premenopausal, perimenopausal, and postmenopausal needs. These requirements pose a high economic burden on the women themselves and on the health care system (Figure 1).

Determining the cost-effectiveness of treatments aimed at relieving VMS is complex. Analysis must consider the direct costs of treatment, costs associated with treatmentrelated adverse events, and the health care costs saved with effective therapy $[37,38]$. Cost-utility analysis of treatment for VMS also considers the impact of treatment on improvements in QOL associated with the alleviation of symptoms. This impact of treatment is expressed in quality-adjusted life years (QALYs) [39].

Since the publication of results from the WHI in 2002, therapy for menopausal symptoms has undergone a dramatic transition. A marked decline has been seen in prescriptions for oral estrogen and HT. Prescriptions for oral estrogens declined from 56.8 million in 2001 to $37.2 \mathrm{mil}$ lion in 2003. The respective values for oral HT were 24.0 and 10.3 million [40]. However, the pendulum has swung from fear to a greater understanding of the risks and benefits of HT [41].

Costs incurred for the management of menopause-related VMS include visits to physicians; follow-up visits and telephone calls for the management of medication-related side effects and changes in medication; self-prescribed over-the-counter remedies, including complementary alternative medications (CAMs); HT; laboratory tests; lost productivity at work; personal costs for hygiene-related supplies; energy costs for the increased use of air conditioning; and extra laundry requirements for clothing and bed sheets soiled with sweat. A recent Gallup poll of menopausal women showed that hot flushes and night sweats were the first-and second-ranked symptoms that prompted physician visits. Among the women surveyed, $70 \%$ complained of hot flushes, $68 \%$ complained of night sweats, 50\% had mood changes and moodiness, and $49 \%$ experienced insomnia and sleeplessness [42]. The costs associated with many of these symptoms have not been quantified, but they undoubtedly result in a significant burden for the women who experience them.

Before seeking medical advice at the onset of VMS, women are likely to obtain information from their peers, family members, or the Internet. In many cases women resort to self-diagnosis and treatment. They may combine over-the-counter drugs with medications prescribed for other conditions (eg, analgesics for headache; anxiolytics and antidepressants for anxiety, tension, and mood changes; sedatives/hypnotics for insomnia). Most of these treatments fail to provide significant relief of VMS, and many women ultimately consult their physicians after these remedies fail. Physician visits for VMS include an initial visit to a primary care physician and, potentially, follow-up visits to a gynecologist or CAM specialist. Subsequent visits and telephone calls are often needed for medication adjustment, laboratory testing, and managing side effects. In addition, women may seek counseling from a psychologist or psychiatrist for mood changes, insomnia, and difficulties with family and social interactions. Women may also visit a neurologist for relief from headaches and/or help with cognitive deficits. All of these factors add to the economic burden of VMS. 


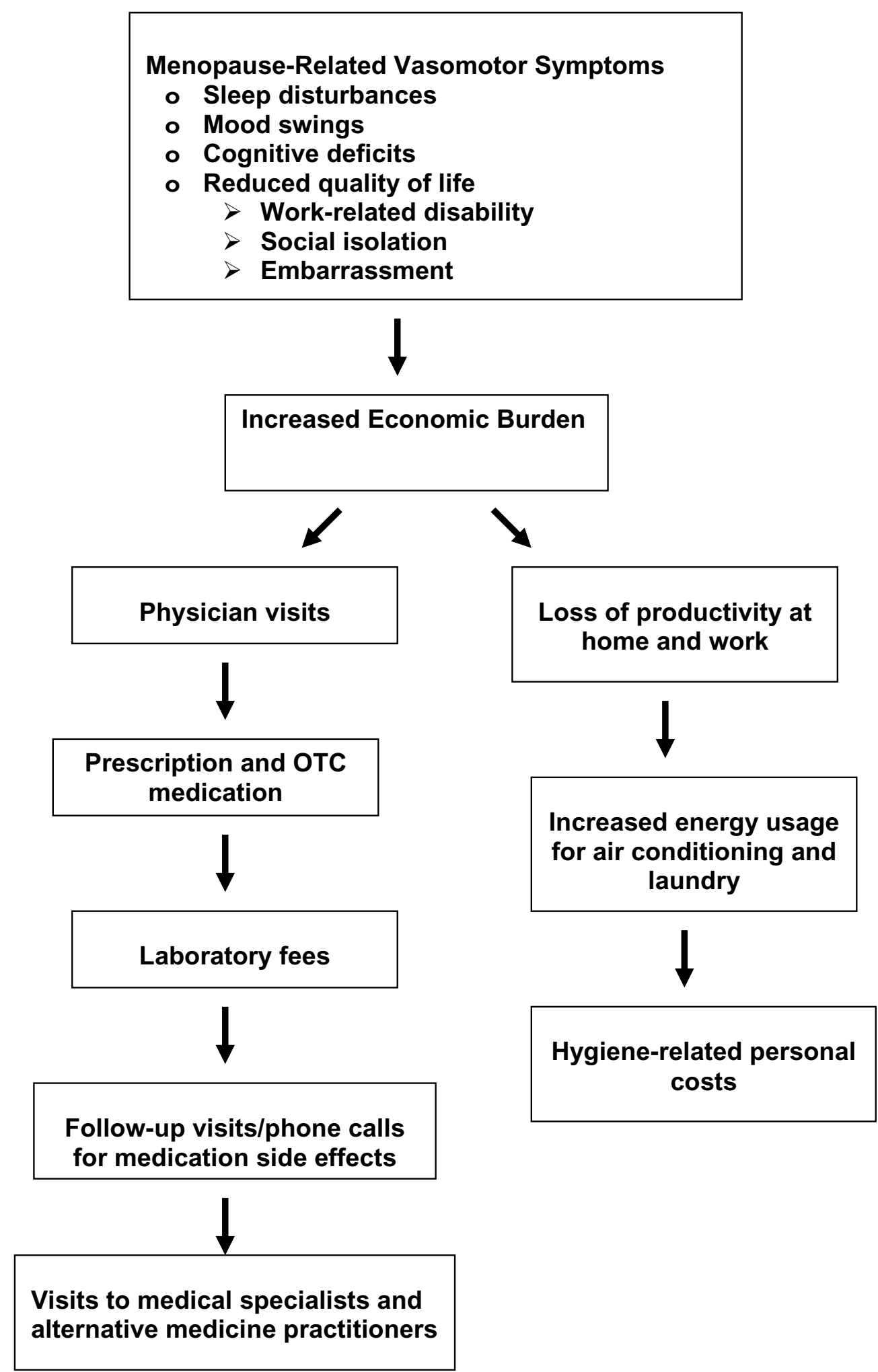

Figure I

Flowchart of factors affecting management costs of menopause related vasomotor symptoms. 
Table 2: Baseline Costs for a Pharmacoeconomic Model of Vasomotor Symptoms

\begin{tabular}{lr}
\hline Drug acquisition costs & $\$ 357$ \\
Norethindrone acetate/ethinyl estradiol & $\$ 474$ \\
Conjugated estrogen/medroxyprogesterone & $\$ 132$ \\
Therapy initiation & $\$ 198$ \\
Two physician visits & $\$ 147$ \\
Breakthrough bleeding at 3 months (or continued spotting at 6 months) \\
$\quad$ Endometrial biopsy \\
Pathology and laboratory fees \\
Telephone call to physician \\
Spotting at 3 months \\
Moderate to severe vasomotor symptoms \\
$\quad$ Two physician visits \\
$90-$ day supply of clonidine \\
\hline
\end{tabular}

Adapted with permission from Botteman et al. [45].

\section{Economic burden of therapy for symptom resolution \\ Hormonal therapy}

The economic burden of VMS management remains high even with the use of HT. Costs associated with HT include one or two visits for diagnosis and medication prescription as well as follow-up visits and telephone calls to manage side effects and evaluate the efficacy of therapy. Serious, but rare, adverse events associated with HT can lead to exceptionally high acute and chronic costs [43]. Evaluation and management of more common transient adverse events, including vaginal and uterine bleeding, breast discomfort, and breast nodularity, can also add significantly to the overall cost of HT for menopause-related symptoms. Approximately one third of patients who use HT switch to another form of therapy or make medication adjustments because of adverse events or compliance problems, increasing the overall cost of therapy [43].

Despite the complexities associated with determining the cost-effectiveness of HT for the treatment of women with menopause, several pharmacoeconomic analyses support the use of such treatment. Results from an early evaluation by Weinstein suggested that HT was cost-effective in menopausal women with prior hysterectomy or osteoporosis, but not in asymptomatic women with an intact uterus. The evaluation included information about the risks of endometrial cancer, uterine bleeding, and gallbladder disease as well as the benefits associated with the relief of menopausal symptoms and prevention of osteoporosis and fractures [44].

Although long-term continuous-combined HT (0.625 $\mathrm{mg}$ /day of conjugated estrogens plus $2.5 \mathrm{mg}$ of medroxyprogesterone [CEE/MPA]) has been associated with the potential for increased health risks in some women, therapy limited to $\leq 5$ years is no doubt beneficial for decreasing VMS, somatic symptoms, and resultant sleep and mood disturbances in women who experience bothersome menopausal symptoms. Moreover, short-term, lowdose therapy may minimize the risk of adverse effects associated with longer-term HT [45]. Botteman and colleagues compared the cost-effectiveness of short-term CEE/MPA $0.625 / 2.5 \mathrm{mg}$ against that of norethindrone acetate $1 \mathrm{mg}$ and ethinyl estradiol $5 \mu \mathrm{g}$ (NA/EE), another continuous-combined HT with a different side-effect profile, and no interventional therapy for the management of moderate to severe VMS [45]. Anticipated 1-year baseline costs for the management of VMS included drug acquisition costs ( $\$ 357$ for NA/EE vs $\$ 474$ for CEE/MPA), initiation of therapy requiring two physician visits (\$132), HTrelated breakthrough bleeding requiring endometrial biopsy and associated visits and laboratory testing (\$345), or spotting requiring a telephone call to the physician (\$16), and two physician visits for VMS plus clonidine therapy (\$162; Table 2) [45]. Results from this analysis indicated that NA/EE was less expensive and more effective than CEE/MPA in QALYs. The cost-effectiveness of NA/EE was greater for patients with severe VMS than those with mild symptoms. NA/EE also was more cost-effective than no treatment, unless the symptoms were so mild that the discomfort of spotting or bleeding (the most common significant adverse effects of short-term HT) offset the QOL improvements associated with HT [45]. It also should be noted that the health risks associated with shorter-term ( 1 to 5 years) HT for the treatment of VMS are not known. Another trial evaluating NA/EE against CEE/MPA $0.625 / 2.5 \mathrm{mg}$ or no therapy in premenopausal and perimenopausal women indicated that NA/EE is costeffective as first-and second-line therapy [46]. Results from this study showed that NA/EE increased costs and QALYs compared with CEE/MPA and no therapy. Despite the increase in direct costs over no therapy and CEE/MPA, the cost effectiveness of NA/EE compared to no therapy is based on a decrease in the cost of treating menopausal symptoms, vaginal bleeding, and hip fractures and 
Table 3: Complementary and Alternative Medicine Costs Over 6 Months

\begin{tabular}{|c|c|c|c|c|}
\hline Product & Main Ingredients & $\begin{array}{l}\text { Cost (\$US) } \\
\text { at I Month }\end{array}$ & $\begin{array}{l}\text { Cost (\$US) } \\
\text { at } 3 \text { Months }\end{array}$ & $\begin{array}{l}\text { Cost (\$US) } \\
\text { at } 6 \text { Months }\end{array}$ \\
\hline Femforte ${ }^{\circledR}$ & Black cohosh, soy isoflavones, androstenedione, chaste berry & 58.00 & 174.00 & 348.00 \\
\hline MACA750 & Organic maca root & 19.95 & 59.85 & 119.70 \\
\hline Promensil ${ }^{\mathrm{TM}}$ & Red clover & 24.95 & 64.90 & 129.80 \\
\hline Remifemin $^{\circledR}$ & Black cohosh extract equivalent to $20 \mathrm{mg}$ dried Cimicifuga rhizome & 49.99 & 78.98 & 157.96 \\
\hline Sleep \& Slim ${ }^{\mathrm{TM}}$ & $\begin{array}{l}\text { L-glutamine, L-lysine } \mathrm{HCl} \text {, magnesium citrate, L-ornithine, glysine, L- } \\
\text { arginine, collagen, vitamin } \mathrm{B}_{6} \text { (pyroxidine } \mathrm{HCl} \text { ), L-carnitine, vitamin } \mathrm{B}_{3} \\
\text { (niacin), aloe vera, ascorbic acid, citric acid, sodium benzoate, } \\
\text { potassium sorbate, carrageenan }\end{array}$ & 49.95 & 149.85 & 299.70 \\
\hline Effisoy $^{\mathrm{TM}}$ & AglyMax: fermented soy germ extract & 29.95 & 79.35 & 149.75 \\
\hline Hot Flash, Non-GMO Soy & $\begin{array}{l}\text { Geneistein-rich soy concentrate, black cohosh root extract, dong } \\
\text { quai root extract, licorice root extract, vitex berry extract }\end{array}$ & 45.98 & 137.94 & 275.88 \\
\hline
\end{tabular}

Note: Three-and 6-month costs that are lower than 3 and 6 times the 1-month costs for certain items reflect bulk prices for the items.

assumes a substantial increase in compliance compared to CEE/MPA as a result of improved control of bleeding with NA/EE. Results from a study reported by Ohsfeldt et al. indicated that the 1-year cost of HT for treating VMS was approximately $\$ 300$ greater than the cost associated with no treatment [47]. It is not clear how results from this Canadian analysis would apply to the United States since health care is much less expensive in that country.

As noted, the published results from the WHI have dramatically reduced the use of estrogen and HT by menopausal women. Results from the WHI prompted reanalysis of the cost-effectiveness of HT by investigators at the Stockholm School of Economics. Generalization of results from this analysis may be limited because Sweden has a national socialized medical system. However, the authors suggest that HT remains a cost-effective therapeutic strategy for women with menopausal VMS compared with no therapy [47].

\section{SSRIs and SNRIs}

Selective serotonin reuptake inhibitors (SSRIs) and serotonin-norepinephrine reuptake inhibitors (SNRIs) have received increased attention for the management of VMS in nondepressed menopausal women [48]. As yet, there have been no pharmacoeconomic analyses of any agents in these classes for this indication. Results from a recent systematic review of published economic evaluations of interventions for depression indicated that SSRIs and SNRIs are more cost-effective than older antidepressant medications (eg, tricyclic antidepressants) owing to their greater efficacy and decreased side-effect profile [49].

\section{Other prescription medications}

Other prescription medications approved for use in conditions not associated with menopause-related VMS have demonstrated varying degrees of efficacy [48]. The eco- nomic advantage for some of these medications is that they have been on the market for a number of years. Given the understanding that the VMS are the result of a dysfunction in thermoregulatory circuitry, new nonhormonal therapies that selectively target the serotonin and norepinephrine pathways, without the involvement of other pathways, seem likely to become the next generation of care for the management of VMS.

\section{CAM treatments}

Many symptomatic menopausal women are likely to treat themselves before consulting a medical practitioner, thinking that "natural" products are safer and the ingredients more pure than synthetic agents. Cost analysis was carried out for CAM treatments that women would commonly find through a basic search on the Internet using the terms complementary medicine and hot flash as search parameters. The most common CAM treatments that emerged were products containing individual and compounded formulas of herbs, isoflavones, and dietary supplements that promised to alleviate menopause-related hot flushes and night sweats, irritability, sleeplessness, mood swings, weight gain, headaches, insomnia, depression, menstrual irregularities, fatigue, and loss of sexual desire. These formulations also claim to promote mental clarity, increase energy levels, and improve physical performance [50-53]. The initial cost of a single product ranged from $\$ 19.95$ to $\$ 58.00$ per month (Table 3). A key limitation in the analysis of these products is that their clinical efficacy has generally not been documented by results from controlled clinical trials. It has also been noted that any benefits associated with herbal supplements may occur more slowly than those achieved with traditional medications [54]. Comparison of 1-year costs of CAM treatments versus HT indicated that three of seven alternative treatments were more expensive than traditional therapy (Table 3). 


\section{Conclusion}

Menopause-related VMS are very common and can be associated with a high patient and societal burden. These symptoms result in high direct and indirect costs and significantly reduced QOL. Current treatments for VMS include HT, prescription medications developed for other indications, and CAM treatments. Short-term HT has been shown to be cost-effective for the management of VMS, but the publicity given the WHI has substantially decreased the use of these treatments. The physiology underlying VMS is complex and not fully understood, but it is clear that alterations in noradrenergic and serotonergic mechanisms during hypothalamic thermoregulation are involved in their development. A significant unmet need remains for menopause-related VMS treatment options. Among women who are eligible for the treatment of menopause-related VMS, $80 \%$ do not seek treatment, receive inadequate counseling, or do not have access to local medical aid [39]. The development of therapies that specifically target VMS may provide high efficacy and reduced risk of serious and potentially costly adverse events, thus increasing the overall cost-effectiveness of therapy.

\section{List of abbreviations \\ BMI Body mass index}

\section{CAM Complementary alternative medication}

CEE/MPA Conjugated estrogens plus medroxyprogesterone acetate

HRQOL Health-related quality of life

HT Hormonal therapy

NA/EE Norethindrone acetate plus ethinyl estradiol

QALY Quality-adjusted life-years

QOL Quality of life

\section{SF-36 36-Item Short Form Health Survey}

SNRI Serotonin-norepinephrine reuptake inhibitor

SSRI Selective serotonin reuptake inhibitor

SWAN Study of Women's Health Across the Nation

UQOL Utian Quality of Life

VMS Vasomotor symptoms

WHI Women's Health Initiative
WHQ Women's Health Questionnaire

\section{References}

I. United States Census 2000. Census 2000 profile 2000:2-5 [www.census.gov]. U.S.Department of Commerce. Economics and Statistics Administration. U.S.Census Bureau

2. Avis NE, Crawford SL, McKinlay SM: Psychosocial, behavioral, and health factors related to menopause symptomatology. Womens Health 1997, 3:103-120.

3. Mohyi $D$, Tabassi $K$, Simon J: Differential diagnosis of hot flashes. Maturitas 1997, 27:203-2|4.

4. Gold EB, Sternfeld B, Kelsey JL, Brown C, Mouton C, Reame N, Salamone L, Stellato R: Relation of demographic and lifestyle factors to symptoms in a multi-racial/ethnic population of women 40-55 years of age. Am J Epidemiol 2000, 152:463-473.

5. Ho SC, Chan SG, Yip YB, Cheng A, Yi Q, Chan C: Menopausal symptoms and symptom clustering in Chinese women. Maturitas 1999, 33:219-227.

6. Whiteman MK, Staropoli CA, Benedict JC, Borgeest C, Flaws JA: Risk factors for hot flashes in midlife women. I Womens Health (Larchmt) 2003, I 2:459-472.

7. Whiteman MK, Staropoli CA, Langenberg PW, McCarter RJ, Kjerulff $\mathrm{KH}$, Flaws JA: Smoking, body mass, and hot flashes in midlife women. Obstet Gynecol 2003, 10 1:264-272.

8. Staropoli CA, Flaws JA, Bush TL, Moulton AW: Predictors of menopausal hot flashes. J Womens Health 1998, 7: I I49-I I 55.

9. Nachtigall LE, Nachtigall MJ: Menopausal changes, quality of life, and hormone therapy. Clin Obstet Gynecol 2004, 47:485-488.

10. Treatment of menopause-associated vasomotor symptoms: position statement of The North American Menopause Society. Menopause 2004, I I: I I-33.

11. Feldman BM, Voda A, Gronseth E: The prevalence of hot flash and associated variables among perimenopausal women. Res Nurs Health 1985, 8:261-268.

12. Deecher DC: Physiology of thermoregulatory dysfunction and current approaches to the treatment of vasomotor symptoms. Expert Opin Investig Drugs 2005, 14:434-448.

13. Kronenberg F: Hot flashes: epidemiology and physiology. Ann N Y Acad Sci 1990, 592:52-86.

14. Freedman RR: Pathophysiology and treatment of menopausal hot flashes. Semin Reprod Med 2005, 23:1 17-125.

15. Utian WH, Janata JW, Kingsberg SA, Patrick LD: Determinants and quantification of quality of life after the menopause: the Utian Menopause Quality of Life score. In The Menopause at the Millenium Edited by: Aso T and Yanaihara T. Taylor \& Francis; 2000:14I-I44.

16. Vliet EL: Menopause and perimenopause: the role of ovarian hormones in common neuroendocrine syndromes in primary care. Prim Care 2002, 29:43-67, vi.

17. McVeigh C: Perimenopause: more than hot flushes and night sweats for some Australian women. J Obstet Gynecol Neonatal Nurs 2005, 34:21-27.

18. Hays J, Ockene JK, Brunner RL, Kotchen JM, Manson JE, Patterson RE, Aragaki AK, Shumaker SA, Brzyski RG, LaCroix AZ, Granek IA, Valanis BG: Effects of estrogen plus progestin on health-related quality of life. N EnglJ Med 2003, 348: 1839-1854.

19. Utian WH, Janata JW, Kingsberg SA, Schluchter M, Hamilton JC: The Utian Quality of Life (UQOL) Scale: development and validation of an instrument to quantify quality of life through and beyond menopause. Menopause 2002, 9:402-410.

20. Reynolds F: Exploring self-image during hot flushes using a semantic differential scale: associations between poor selfimage, depression, flush frequency and flush distress. Maturitas 2002, 42:20I-207.

21. Ledesert B, Ringa V, Breart G: Menopause and perceived health status among the women of the French GAZEL cohort. Maturitas 1994, 20: II3-120.

22. Burton WN, Pransky G, Conti DJ, Chen CY, Edington DW: The association of medical conditions and presenteeism. J Occup Environ Med 2004, 46:S38-S45.

23. Bobula JD: Vasomotor symptoms and quality of life (QoL) in postmenopausal women. Value Health 2003, 6 Number 6:707.

24. Stewart WF, Van Rooyan JB, Cundiff GW, Abrams P, Herzog AR, Corey R, Hunt TL, Wein AJ: Prevalence and burden of overactive bladder in the United States. World J Urol 2003, 20:327-336. 
25. Polo-Kantola P, Erkkola R: Sleep and the menopause. J Br Menopause Soc 2004, 10:145-150.

26. 1998 Women and Sleep Poll 1998 [www.sleepfoundation.org/ publications/I998womenpoll.cfm]. National Sleep Foundation

27. Young T, Finn L, Austin D, Peterson A: Menopausal status and sleep-disordered breathing in the Wisconsin Sleep Cohort Study. Am J Respir Crit Care Med 2003, I 67: I I8I- I I85.

28. Moe KE: Hot flashes and sleep in women. Sleep Med Rev 2004, 8:487-497.

29. Amore M, Di Donato P, Papalini A, Berti A, Palareti A, Ferrari G, Chirico C, De Aloysio D: Psychological status at the menopausal transition: an Italian epidemiological study. Maturitas 2004, 48: II5- 124

30. Collins A, Landgren BM: Reproductive health, use of estrogen and experience of symptoms in perimenopausal women: a population-based study. Maturitas 1994, 20: I0 I- I I I.

31. Soares CN, Joffe H, Steiner M: Menopause and mood. Clin Obstet Gynecol 2004, 47:576-59I.

32. Bromberger JT, Meyer PM, Kravitz HM, Sommer B, Cordal A, Powell L, Ganz PA, Sutton-Tyrrell K: Psychologic distress and natural menopause: a multiethnic community study. Am J Public Health 200I, 9 I:|435-|442.

33. Dennerstein L, Guthrie JR, Clark M, Lehert P, Henderson VW: A population-based study of depressed mood in middle-aged, Australian-born women. Menopause 2004, I I:563-568.

34. Cohen LS, Soares CN, Poitras JR, Prouty J, Alexander AB, Shifren JL: Short-term use of estradiol for depression in perimenopausal and postmenopausal women: a preliminary report. Am J Psychiatry 2003, 160:1519-1522.

35. Shepherd JE: Effects of estrogen on congnition mood, and degenerative brain diseases. I Am Pharm Assoc (Wash) 2001, 41:221-228.

36. Jacobs DM, Tang MX, Stern Y, Sano M, Marder K, Bell KL, Schofield $P$, Dooneief $G$, Gurland B, Mayeux R: Cognitive function in nondemented older women who took estrogen after menopause. Neurology 1998, 50:368-373.

37. Tosteson AN, Weinstein MC: Cost-effectiveness of hormone replacement therapy after the menopause. Baillieres Clin Obstet Gynaecol 1991, 5:943-959.

38. Tosteson ANA, Weinstein MC, Schiff I: Cost-effectiveness analysis of hormone replacement therapy. In Treatment of the Postmenopausal Woman: Basic and Clinical Aspects Volume 5I. Second edition. Edited by: Lobo RA. Philadelphia, Pennsylvania, Lippincott Williams \&Wilkins; 1999:557-565.

39. Whittington R, Faulds D: Hormone replacement therapy: I. A pharmacoeconomic appraisal of its therapeutic use in menopausal symptoms and urogenital estrogen deficiency. Pharmacoeconomics 1994, 5:419-445.

40. Hersh AL, Stefanick ML, Stafford RS: National use of postmenopausal hormone therapy: annual trends and response to recent evidence. JAMA 2004, 29 I:47-53.

41. Utian WH: Pieter van Keep Memorial Lecture. Menopause--a modern perspective from a controversial history. Maturitas 1997, 26:73-82.

42. The 2002 Gallup study of consumers' and physicians' changing HRT concerns. Qualitative Phase I \& II. Volume MS 22085. Princeton, New Jersey, Multi-Sponsor Surveys, Inc; 2002: I-90.

43. Ohsfeldt RL, Gavin NI, Thorp JM: Medical care costs associated with postmenopausal estrogen plus progestogen therapy. Value Health 2004, 7:544-553.

44. Weinstein MC: Estrogen use in postmenopausal women-costs, risks, and benefits. $N$ Engl J Med 1980, 303:308-316.

45. Botteman MF, Shah NP, Lian J, Pashos CL, Simon JA: A cost-effectiveness evaluation of two continuous-combined hormone therapies for the management of moderate-to-severe vasomotor symptoms. Menopause 2004, I I:343-355.

46. Coyle D, Cranney A, Tugwell P: Economic evaluation of norethisterone acetate/ethinylestradiol (FemHRT) for women with menopausal symptoms. Pharmacoeconomics 2003, 21:661-669.

47. N Z, F B, B J, J K: A re-assessment of the cost-effectiveness of hormone replacement therapy in Sweden--results based on the Women's Health Initiative randomised controlled trial. Volume 57I. Stockholm, Sweden, Stockholm School of Economics, Centre for Health Economics; 2004: I-38.
48. Fugate SE, Church CO: Nonestrogen treatment modalities for vasomotor symptoms associated with menopause. Ann Pharmacother 2004, 38: |482-| 499.

49. Barrett B, Byford S, Knapp M: Evidence of cost-effective treatments for depression: a systematic review. J Affect Disord 2005, 84: 1 - I3.

50. Source Naturals -Hot Flash, 180 tablets 2005 [www.clubnatu ral.com/hotflnosol 80.html].

5I. Maca 750 for hot flashes, night sweats, fatigue and low libido 2005 [www.medicine-plants.com].

52. Sleep \& Slim. The healthy all natural way to lose weight 2005 [www.sleep-n-slim-weight-loss.com].

53. Femforte - managing the symptoms of menopause 2005 [www.natmedlabs.com].

54. Kronenberg F, Fugh-Berman A: Complementary and alternative medicine for menopausal symptoms: a review of randomized, controlled trials. Ann Intern Med 2002, 137:805-8I3.

Publish with Bio Med Central and every scientist can read your work free of charge

"BioMed Central will be the most significant development for disseminating the results of biomedical research in our lifetime. "

Sir Paul Nurse, Cancer Research UK

Your research papers will be:

- available free of charge to the entire biomedical community

- peer reviewed and published immediately upon acceptance

- cited in PubMed and archived on PubMed Central

- yours - you keep the copyright

Submit your manuscript here:

http://www.biomedcentral.com/info/publishing_adv.asp
BioMedcentral 